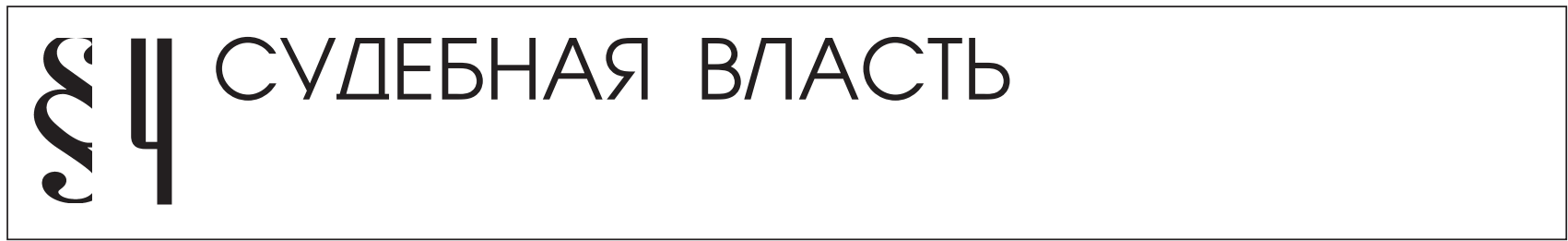

\title{
ПРЕДПОСЫЛКИ И ПЕРСПЕКТИВЫ ВНЕДРЕНИЯ ЭЛЕКТРОННОЙ ФОРМЫ УГОЛОВНОГО ДЕЛА В ДЕЯТЕЛЬНОСТЬ СУДЕБНЫХ ОРГАНОВ
}

\begin{abstract}
Аннотация: Целью работы является исследование электронной формы уголовного дела, а также выявление предпосылок для использования этой технологии судами в уголовном судопроизводстве и определение правовых, технических и соичильных барьеров, препятствующих ее внедрению. В качестве метода, изучающего предмет исследования, используется анализ норм уголовно-процессуального законодательства, федеральных иелевых программ, а также мнений ученых и практикующих специиалистов по поводу возможности внедрения и использования современных иңифровых технологий в деятельности судебных органов.

Результаты работы и выводы. Ряд ученых и практикующих специиалистов всецело отдают предпочтение новым и прогрессивным технологиям в уголовном судопроизводстве, в том числе и электронному уголовному делу. Кроме того, федеральные иелевые программы, посвященные развитию судебной системы в России, содержат ряд предпосылок, «подталкивающих» судебную реформук внедрению электронного уголовного дела. На наш взгляд, иелесообразнее уже в ближайшие годы разработать федеральные иелевые программы для развития и совершенствования досудебного уголовного судопроизводства. Имеющееся в уголовно-прочессуальном законодательстве задель по использованию современных технологий позволят технически испьтать первые образиь электронного уголовного дела в ближайшее десятилетие без каких-либо существенных изменений Уголовно-процессуального кодекса РФ. Однако в любом случае в перспективе потребуется законодательно урегулировать возможность применения данной технологии, заблаговременно устранить барьеры и разрешить проблемные ситуации, которые могут возникнуть при внедрении электронной формы уголовного дела.
\end{abstract}

Ключевые слова: Юриспруденция, судопроизводство, уголовный, процесс, суд, технология, электронный, носитель, информация, программа

овременный мир и современные технологии выдвигают для общества и государства новые правила и требования, определяя направления для совершенствования государственного устройства и правового процесса. В последнее время происходит ускорение всех процессов и циклов в различных сферах деятельности человека и государства. В связи с этим С.М. Плешаков отмечает, что «по мере возрастания научных открытий и разнообразных изобретений рабочие места оснащаются всевозможными научно-техническими новинками, видоизменяются технологические процессы, происходит компьютеризация отдельных операций»1.

Не остается в стороне от эволюционного изменения и отечественное уголовное судопроизводство, где также происходит преобразование отдельных институтов и

\footnotetext{
${ }^{1}$ См.: Плешаков С.M. Современные экспертные технологии в деятельности судебно-экспертных учреждений России: автореферат дис. ... канд. юрид. наук; 12.00.09. Нижний Новгород, 2007. С.5-6.
}

ускорение процессов, а любое промедление в деятельности следователей и судей в настоящее время недопустимо. Например, ч. 5 ст. 6.1 УПК РФ, закрепляющая принцип разумного срока уголовного судопроизводства, устанавливает, что «в случае если после поступления уголовного дела в суд дело длительное время не рассматривается и судебный процесс затягивается, заинтересованные лица вправе обратиться к председателю суда с заявлением об ускорении рассмотрения дела» ${ }^{2}$. Кроме того, Федеральный закон №68-Ф3 от 30.04.2010 г. «О компенсации за нарушение права на судопроизводство в разумный срок» в ст. 1 закрепляет, что «Граждане РФ... являющиеся в судебном процессе сторонами... при нарушении их права на судопроизводство в разумный срок... могут обратиться в суд... с заявлением о присуждении

\footnotetext{
2 Уголовно-процессуальный кодекс Российской Федерации от 18.12.2001 г. №174-Ф3 (по состоянию на 01.10.2012 г.) // Собрание законодательства РФ. 2001. №52 (часть 1). Ст. 4921.
} 
компенсации за такое нарушение в порядке, установленном настоящим Федеральным законом и процессуальным законодательством Российской Федерации»³.

Как показывает анализ судебной практики, число подобных заявлений растет с каждым годом, равно как и размер компенсации. Так, в сентябре 2010 года осужденным была присуждена компенсация за нарушение права на судебное разбирательство в разумный срок (расследование и рассмотрение уголовного дела длилось свыше 11 лет) в размере 288400 рублей, причем данное уголовное дело отличалось определенной сложностью: было привлечено к ответственности 12 лиц, потерпевших было 13 лиц, допрошено 74 свидетеля, объем уголовного дела составил 52 тома 4 .

Для того чтобы в будущем избежать подобных негативных последствий, связанных с затягиванием расследования и рассмотрения уголовного дела, необходимо использование новых современных технологий, которые позволят уголовному судопроизводству уложиться в разумные сроки, оптимизировать и рационализировать судебный процесс и соблюсти при этом права и законные интересы граждан. Нет сомнений в том, что значительная часть времени у сотрудников следственного и судебного аппарата тратится на составление процессуальных документов, включая многократное переписывание и распечатку на принтере, причем для соответствующей «материализации» всех собранных по уголовному делу сведений может уйти значительное количество бумажных ресурсов. Очевидно, что нынешний вид уголовных дел на сегодняшний день представляет собой своеобразный пережиток прошлого.

Исторически сложилось так, что бумага является основным носителем информации по уголовному делу. Различные следственные действия, решения следователя и суда так или иначе находят отражение в письменных процессуальных документах. Даже фотографии, полученные по результатам осмотра места происшествия и иных следственных и процессуальных действий, приобщались к уголовному делу в качестве фототаблиц, оформленных на бумажном носителе. Сложность и многоэпизодность уголовного дела, многочисленные судебные экспертизы, значительное число обвиняемых, свидетелей и потерпевших неизбежно приводит к большому количеству материалов расследования, что, в свою очередь, способствует появлению на свет объемных и тяжеловесных томов уго-

\footnotetext{
${ }^{3}$ Федеральный закон от 30.04.2010 №68-Ф3 «О компенсации за нарушение права на судопроизводство в разумный срок или права на исполнение судебного акта в разумный срок» // Собрание законодательства РФ, 03.05.2010, №18, ст. 2144.

${ }^{4}$ Решение Верховного Суда РФ от 23.09.2010 №ГКПИ10-862// Сайт Верховного суда РФ. URL: www.vsrf.ru (дата обращения 11.10.2012).
}

ловного дела. Судебная практика знает немало случаев, когда объем уголовного дела составлял свыше 100 томов 5 . Кроме того, бумага никак не защищена от воздействия огня, вследствие чего уголовное дело легко поддается уничтожению. К сожалению, судебная практика знает ряд случаев, когда уголовные дела подвергались своеобразной девастации и вместе с ними исчезали бесследно все сведения о преступлениях и о лицах, их совершивших 6 .

Поэтому одним из первых шагов в модернизации уголовного судопроизводства должен стать переход на новую форму уголовного дела и отказ от бумажных процессуальных документов. В свете этого предлагается в качестве альтернативы использовать электронную форму уголовного дела, которая должна в значительной мере упростить процедуры собирания доказательств и составления процессуальных документов.

Это должен быть электронный носитель, предназначенный для хранения цифровой информации - материалов уголовного дела, полностью заменяющий собой бумажный вариант уголовного дела, позволяющий использовать его совместно с портативным компьютером для собирания доказательств в рамках расследования и рассмотрения уголовного дела. При этом в данном цифровом носителе должна быть заложена программа по формированию уголовного дела, содержащего в себе алгоритм последовательных действий (движения уголовного дела) с момента возбуждения дела и до момента исполнения приговора, включающий в себя бланки и шаблоны отдельных процессуальных документов (например, протокол осмотра происшествия или протокол предъявления для опознания, графы которых будут заполняться необходимой информацией) и позволяющий прикреплять к данным документам в электронной форме все сведения о полученных доказательствах, включая фото-, кино- и видеоизображения, а также иные файлы и программные продукты. Электронная форма уголовного дела может

\footnotetext{
${ }^{5}$ Например, по делу АО «МММ» было приостановлено рассмотрение уголовного дела в связи с тем, что обвиняемый Сергей Мавроди в период с 21 октября 2003 года по 31 января 2006 год знакомился с материалами уголовного дела. Общий объем материалов уголовного дела составлял 610 томов. // Срок ознакомления Мавроди с материалами дела признан законным // Сайт «РИА Новости», 15.03.2005. URL: http://www.ria.ru/incidents/20050316/39527311 (Дата обращения: 20.10.2012).

${ }^{6}$ Так, 10 февраля 1999 года сгорело здание Самарского ГУВД. При этом погибло 57 человек, а в ходе пожара в огне уничтожены материалы операции «Циклон», связанные с расследованием уголовных дел по преступлениям, совершенными Тольяттинскими группировками. По мнению Российской газеты, «пожар выгоден был многим нечистым на руку людям и откровенным бандитам. В оперативных и следственных органах тогда находилось немало громких дел, в том числе и по хищениям на ВАЗе». / Следы на пепелище //Сайт «Российская газета» - Поволжье. 10 февраля 2004. №3401. URL: http://www.rg.ru (дата обращения 22.10.2012).
} 


\section{Право и политика $1(157) \cdot 2013$}

ограничиться всего лишь одним цифровым, но прочным носителем, в котором будут содержаться все материалы по делу либо по нескольким делам.

В связи с этим, на данный момент целесообразнее определить не технические характеристики электронной формы уголовного дела, а предопределить возможность появления данной технологии в ближайшие годы и выявить, какие имеются законодательные и процессуальные предпосылки для внедрения электронной формы дела в уголовное судопроизводство Российской Федерации.

Для начала следует отметить, что Уголовнопроцессуальный кодекс РФ содержит в своих нормах положения по применению современных технологий при расследовании и рассмотрении уголовного дела. Так, согласно ч. 6 ст. 164 УПК РФ, «при производстве следственных действий могут применяться технические средства и способы обнаружения, фиксации и изъятия следов преступления и вещественных доказательств». В ч. 2 ст. 166 УПК РФ указано, что « протокол может быть написан от руки или изготовлен с помощью технических средств». А в ч. 5 ст. 166 УПК РФ отмечено следующее: «в протоколе должны быть указаны также технические средства, примененные при производстве следственного действия, условия и порядок их использования, объекты, к которым эти средства были применены, и полученные результаты. В протоколе должно быть отмечено, что лица, участвующие в следственном действии, были заранее предупреждены о применении при производстве следственного действия технических средств». Согласно ч. 2 ст. 259 УПК РФ, «протокол может быть написан от руки, или напечатан на машинке, или изготовлен с использованием компьютера. Для обеспечения полноты протокола при его ведении могут быть использованы стенографирование, а также технические средства». В соответствии с ч. 2 ст. 303 УПК РФ: «приговор должен быть написан от руки или изготовлен с помощью технических средств одним из судей, участвующих в его постановлении» 7.

Проанализировав изложенные нормы, можно отметить, что уголовно-процессуальный закон толкует понятие «технические средства» очень широко, разрешая при этом участникам уголовного судопроизводства использовать любые цифровые устройства для работы с материалами уголовного дела. Не исключено, что и электронное уголовное дело может подпадать под понятие «технические средства», так как функции указанного девайса совпадают с параметрами иных цифровых устройств, используемых органами следствия, дознания и суда при расследовании и разрешении уголовных дел. Отдельно стоит отметить тот факт, что летом 2012 года в уголовно-процессуальном

${ }^{7}$ См.: Уголовно-процессуальный кодекс Российской Федерации от 18.12.2001 г. №174-Ф3 (по состоянию на 01.10.2012 г.) // Собрание законодательства РФ. 2001. №52 (часть 1). Ст. 4921. законодательстве было закреплено понятие «электронный носитель информации». Так, согласно п. 5 ч. 2 ст. 82 УПК РФ, «Вещественные доказательства в виде электронных носителей информации: а) хранятся в опечатанном виде в условиях, исключающих возможность ознакомления посторонних лиц с содержащейся на них информацией и обеспечивающих их сохранность и сохранность указанной информации; б) возвращаются их законному владельцу после осмотра и производства других необходимых следственных действий, если это возможно без ущерба для доказывания» ${ }^{8}$.

В данном случае речь идет именно только о тех цифровых носителях, которые были изъяты у участников уголовного судопроизводства, в том числе и в ходе следственных действий, и были приобщены к материалам дела в качестве доказательств. Причем под электронными цифровыми носителями, исходя из толкования уголовно-процессуального закона, имеются в виду различные твердотельные накопители информации: USB-флешки, карты памяти, SSD-диски и т.п., а также шпиндельные накопители информации: HDD-диски, CD/DVD/BlueRay-диски и т.п. Следует отметить, что по смысловому значению понятие “электронный носитель информации” очень близко к понятию “электронная форма уголовного дела”, и имеют очень схожие конструктивные и технические характеристики, причем с процессуальной точки зрения эти носители позволяют накапливать и хранить в цифровом виде разнообразные материалы уголовного дела, включая как электронные документы, так фотографии и видеофайлы.

Тем самым, можно заметить, что Уголовно-процессуальным кодексом РФ заблаговременно предусмотрены условия для внедрения электронной формы уголовного дела, в том числе, благодаря содержащимся в нормах расширенным понятиям «технические средства»и «электронный носитель информации». Однако уголовнопроцессуальное законодательство не является единственной предпосылкой для внедрения электронной формы уголовного дела в уголовное судопроизводство.

Существенное значение для интеграции современных технологий, в частности, электронного уголовного дела в уголовное судопроизводство придали федеральные целевые программы “Развитие судебной системы России” на 2002-2006 годы и на 2007-2012 годы9, и особенно феде-

\footnotetext{
${ }^{8}$ См.: Федеральный закон от 28.07.2012 №143-Ф3 «О внесении изменений в Уголовно-процессуальный кодекс Российской Федерации» // Собрание законодательства РФ, 30.07.2012. №31, ст. 4332.

${ }^{9}$ См.: Постановление Правительства РФ от 20.11.2001 №805 (ред. от 06.02.2004) «О федеральной целевой программе «Развитие судебной системы России» на 2002-2006 годы// Собрание законодательства РФ, 03.12.2001, №49, ст. 4623; Постановление Правительства РФ от 21.09.2006 №583 (ред. от 13.06.2012) «О федеральной целевой программе «Развитие судебной системы
} 
ральная целевая программа «Развитие судебной системы России на 2013-2020 годы», чья концепция была утверждена Правительством России 20 сентября 2012 года ${ }^{10}$.

Как известно, «первая» федеральная целевая программа наряду с реконструированием судов и повышением престижа, эффективности и качества судопроизводства предусматривала замену разрозненной и устаревшей вычислительной техники на компьютеры и создание в судах компьютерных автоматизированных рабочих мест для судей, помощников судей и работников аппаратов судов, локальных вычислительных сетей, оснащенных централизованными и общедоступными информационно-правовыми и другими информационными ресурсами. Следующая федеральная целевая программа вместе с обеспечением доступности и открытости правосудия определила создание информационно-коммуникационной системы Верховного Суда Российской Федерации, интегрированной с информационной системой судов общей юрисдикции «Государственная автоматизированная система Российской Федерации «Правосудие»», а также формирование необходимой телекоммуникационной инфраструктуры для обеспечения эффективного взаимодействия судов общей юрисдикции. В частности, на базе ГАС «Правосудие» были созданы сайты судов общей юрисдикции, предоставляющие гражданам ценнейшую информацию о судопроизводстве, в том числе о рассматриваемых делах и о решениях, принятых судом по каждому делу ${ }^{11}$.

Большинство перечисленных в Федеральных целевых программах мероприятий были реализованы на практике, в связи с чем суды стали технологически сформированы. Следует отметить, что благодаря выполненным мероприятиям была создана благодатная «почва» для внедрения в суд технологий нового поколения, в том числе и для электронной формы уголовного дела.

Между тем федеральная целевая программа «Развитие судебной системы России» на 2013-2020 годы содержит в себе много новых принципиально важных мер, связанных с внедрением отдельных видов технологий в уголовный процесс и предусматривает создание условий для электронного судопроизводства, предусматривающего

России» на 2007-2012 годы // Собрание законодательства РФ, 09.10.2006, №41, ст. 4248.

${ }^{10}$ См.: Распоряжение Правительства РФ от 20.09.2012 №1735-р «Об утверждении федеральной целевой программы «Развитие судебной системы России» на 2013-2020 годы» // Собрание законодательства РФ, 01.10.2012, №40, ст. 5474.

${ }^{11}$ См.: Абдулвалиев А.Ф. О необходимости использования Интернет-сайтов судов общей юрисдикции с целью формирования правовой культуры в молодежной среде // Современное состояние государственной молодежной политики: опыт и проблемы: Материалы Региональной научно-практической конференции / под ред. Исуповой Е.А. - Нижневартовск: Изд-во НГГУ, 2011. С.3-10. упрощение процедур, в том числе и для подачи жалоб в электронной форме. В частности, предлагается создание «облачной» вычислительной архитектуры, которая позволит максимально эффективно, надежно и безопасно использовать технологии и специализированное «облачное» программное обеспечение для автоматизации судебного и общего делопроизводства, что в дальнейшем существенно сократит затраты на развертывание, поддержку и модернизацию программного обеспечения. Решение этих задач позволит реализовать возможность удаленного доступа как со стороны судов, так и со стороны участников судебных процессов из любой точки страны и мира, и с любого устройства, в том числе мобильного. Кроме того, предлагается расширение возможностей использования мобильных устройств в качестве доступа к информационным ресурсам, программным комплексам и базам данных арбитражных судов Российской Федерации посредством использования «облачных» технологий для судей и работников аппарата судов - мобильного правосудия, то есть теперь любой участник уголовного судопроизводства сможет приносить в суд ходатайства, заявления и жалобы в электронной форме на своих мобильных устройствах, а у самого суда появится возможность напрямую через «облачную» программную систему напрямую получать информацию из баз данных и от других органов (в том числе и между судами), минуя письменные запросы. Нет сомнений в том, что подобный задел позволит в дальнейшем интегрировать в судебный процесс новые технологии и облегчит процедуру внедрения электронной формы уголовного дела.

Но самой важной новеллой федеральной целевой программы является создание пилотного проекта «Электронное дело», суть которого заключается в организации входного сканирования всех поступающих в суды документов и формирование электронных дел. Очевидно, что здесь речь идет как раз об электронной форме дела, применение которого планируется в первую очередь в арбитражных судах. Именно этому суду предстоит «проложить дорогу» использования электронной формы дела и наработать практику ее применения для других судов, в том числе для рассмотрения и разрешения уголовного дела.

Стоит также отметить, что новая федеральная целевая программа впервые вышла за рамки судебной деятельности, предусмотрев ряд мероприятий для модернизации экспертной деятельности и модернизации Федеральной службы судебных приставов в рамках исполнения судебных решений. В частности, с целью повышения уровня оперативности проведения судебных экспертиз предлагается обеспечить создание и ведение единого федерального банка данных судебных экспертиз и экспертных организаций путем, например, внедрения компонентов автоматизированной системы в судебно-экспертных уч- 


\section{Право и политика 1 (157) 2013}

реждениях и их подразделениях, и создания ведомственного удостоверяющего центра для возможности применения электронной цифровой подписи. В рамках повышения прозрачности и доступности системы принудительного исполнения для сторон исполнительного производства, уровня оперативности действий должностных лиц государства в ходе исполнения требований исполнительных документов предлагается создание электронного архива для хранения электронных документов с целью перехода на принудительное исполнение в электронном виде, а также создание вычислительной инфраструктуры банка данных исполнительных производств регионального уровня, объединенной общей средой мониторинга и репликации данных в каждый территориальный орган Федеральной службы судебных приставов.

В целом, подобная электронная и информационная интеграция позволит объединить всю судебную систему вместе с экспертными органами и службой судебных приставов в единую коммуникационную сеть, что полностью исключит в дальнейшем какой-либо бумажный документооборот и позволит вплотную подойти к реализации электронной формы уголовного дела в будущем. Есть все основания полагать, что и после 2020 года последующая Федеральная целевая программа предусмотрит модернизацию иных институтов и органов, чья деятельность непосредственно связана с правосудием.

На сегодняшний день имеются ряд научно-технических разработок-прототипов, касающихся частичного использования электронной формы уголовного дела. Речь идет об автоматизированной информационно-справочной системе (далее - АИСС) «Досудебное производство 2011», разработанной в 2005 г. Научно-исследовательским институтом проблем укрепления законности и правопорядка при Генеральной прокуратуре Российской Федерации с целью информационной поддержки процессуальной деятельности следственных работников военной прокуратуры на стадиях досудебного производства. Автоматизированная информационно-справочная система включает в себя модули программного комплекса АИСС «Досудебное производство 2011/1», которые предназначены для работы в условиях, когда невозможно использование стационарного персонального компьютера (работа на месте происшествия или допрос в следственном изоляторе с использованием ноутбука, проведение следственных действий при выезде в командировки, когда предоставляется возможность использовать любой компьютер). Программный комплекс АИСС построен таким образом, что он не требует установки его на жесткий диск компьютера и может работать со сменного носителя информации (например, USB Flash). При использовании АИСС «Дежурный следователь 2011/01» на разных ПК для перемещения программного комплекса АИСС между ними рекомендуется использовать USB Flash - накопитель. Структура «электронного уголовного дела» представляет собой систему вложенных папок. Единообразие системы папок призвано способствовать большей упорядоченности хранения документов (их электронных копий) уголовного дела, ускорению поиска материалов другим следователем (пользователем) в переданном ему электронном уголовном деле. Как отмечают авторы, описавшие данную технологию, использование электронного уголовного дела повысит эффективность работы, унификацию и автоматизацию документооборота, сохранность документов, читабельность документов и снизит уровень грамматических ошибок» ${ }^{12}$.

Исходя из приведенного примера, можно заявить следующее: реализация программы по внедрению электронной формы уголовного дела уже началась. Правда, речь идет только об отдельных программных обеспечениях, способных в последующем значительно облегчить работу следователям, дознавателям, прокурорам и судьям, но в тоже время необходимо констатировать, что данная разработка является частной, и данная технология была сгенерирована научно-исследовательскими институтами по заказу работников военной прокуратуры и сотрудников военного гарнизонного суда.

Если же анализировать мнения ученых и практикующих специалистов по поводу новых современных технологий в уголовном судопроизводстве, то можно выделить следующие моменты. Важно отметить тот факт, что в научных кругах постепенно встает вопрос об использовании электронных дел в судопроизводстве, которые будут содержать в себе электронные документы и доказательства. Обосновывая правовые позиции использования электронной формы уголовного дела, ряд молодых ученых отмечает, что «правовая основа для введения электронного протокола в уголовный процесс, можно сказать, уже сформирована. Кроме того, основные требования, предъявляемые к электронным документам, представляемым в качестве доказательств в уголовном процессе, уже содержатся в п. 6 ч. 2 ст. 74 и ч. 2 ст. 8 УПК РФ"'13. Применительно к электронному протоколу О.В. Тульская пишет, что “такие документы должны быть составлены в ходе следственного действия или непосредственно после его окончания, содержать указание на место, дату и время его производства, необходимые персональные данные участников, описание его проведения и полученных при этом результатов, а также применением технических средств, замечания участников и быть за-

\footnotetext{
12 Настольная книга военного прокурора: пособие (под общ. ред. заместителя Генерального прокурора Российской Федерации С.Н. Фридинского). М.: «За права военнослужащих». 2012.

${ }^{13}$ См.: Гарифуллина А.Х., Сухарева О.С. Электронный протокол как новый вид доказательства и новый элемент удостоверительного аспекта уголовного судопроизводства // Вестник Казанского юридического института МВД России. 2012. № 9. С. 111-117.
} 
верены в установленном порядке электронно-цифровой подписью соответствующих должностных лиц"14.

В связи с этим, до недавнего времени среди органов предварительного расследования и в судебной системе электронные документы не получили достаточного распространения, что связано в том числе и со сложностью их составления, и с тем, что для них фактически еще не нашлось своего законного места у правоприменителя. Однако судебные органы уже готовы пойти на столь революционный шаг, и первые движения в этом направлении уже имеются.

В 2011 году во время интернет-конференции Генерального директора Судебного департамента при Верховном Суде Российской Федерации Гусева Александра Владимировича было заявлено, что «судопроизводство в России широко начало использовать современные достижения информационных технологий во всех органах судебной власти в субъектах Российской Федерации, включая и мировую юстицию. В области информационных технологий процессы ввода новых технологических подходов на 70-80\% происходят каждые 5 лет, а для судебной власти качественная сторона обновлений вносит практически новые решения в судопроизводстве, в том числе и в процедурные вопросы». Кроме того, во время Интернет-конференции было заявлено, что в «перспективе необходимо решить задачу получения судами материалов дел, исковых заявлений, жалоб в виде электронного документа, в том числе подписанных электронной цифровой подписью. Потребуется дополнительная проработка вопросов обеспечения информационной безопасности, формирование удостоверяющих центров» ${ }^{15}$.

Очевидно, что судебные органы заинтересованы во введении в ближайшем будущем подобных цифровых технологий, включая электронную форму уголовного дела. Нет сомнений в том, что и следственные органы, а также органы прокуратуры и дознания заинтересованы в использовании электронного уголовного дела.

Однако, как и у любой новой технологии, внедрению электронной формы уголовного дела могут помешать определенные барьеры, которые не позволят в должной и полной мере реализовать задуманное.

Во-первых, без проработки на сегодняшний день системы защиты электронного уголовного дела и элек-

\footnotetext{
${ }^{14}$ Тульская О.В. Некоторые проблемы использования электронных документов в качестве доказательств в уголовном судопроизводстве // Вестник Академии Генеральной прокуратуры РФ. №6 (14). 2009. C.74-79.

${ }^{15}$ Интернет-конференция Генерального директора Судебного департамента при Верховном Суде Российской Федерации Гусева Александра Владимировича «Актуальные вопросы деятельности Судебного департамента при Верховном Суде Российской Федерации: проблемы и перспективы». 10.08.2011 // URL: www.garant. ru (дата обращения: 25.10.2012).
}

тронных баз данных от вредоносных программ, несанкционированного доступа и хакерских атак невозможно будет внедрить данные технологии в уголовное судопроизводство и спокойно использовать их; к сожалению, могут найтись «недоброжелатели», которые готовы будут стремиться к получению всех сведений по уголовным дела с целью дальнейшей перепродажи и шантажа, либо к полному уничтожению материалов дела. Кроме того, предстоит соблюсти требование, изложенное в ст. 161 УПК РФ, и касающееся недопустимости разглашения данных предварительного расследования. Не исключено, что возможны различные утечки информации из материалов уголовных дел, в связи с чем уже сейчас необходимо продумать систему предотвращения потери данных из электронной формы уголовного дела ${ }^{16}$.

Во-вторых, необходимо решить вопрос, связанный с оснащением всех следственных органов, органов дознания и прокуратуры мобильными автоматизированными системами и технологиями для того, чтобы указанные участники уголовного судопроизводства могли беспрепятственно и свободно заниматься расследованием уголовного дела, а также своевременно, оперативно и качественно формировать электронные материалы дела.

В-третьих, предстоит решить проблему, связанную с унификацией процессуальных форм электронного уголовного дела для того, чтобы во всех регионах и во всех структурных подразделений следствия, дознания, прокуратуры и суда был единый стандарт (единое программное обеспечение) по формированию уголовного дела с целью исключения какого-либо видоизменения или фальсификации документов.

В-четвертых, очень важно при использовании «электронного уголовного дела» не допустить какого-либо нарушения или ущемления прав участников уголовного судопроизводства (особенно подозреваемого, обвиняемого или потерпевшего), что, в свою очередь потребует, внесения глобальных изменений в существующее процессуальное законодательство.

В-пятых, для успешного использования технологии электронного уголовного дела необходимо, чтобы все в обществе умели свободно пользоваться компьютерными технологиями, поскольку в настоящий момент до сих пор не все граждане нашей страны овладели подобными навыками (особенно старшее поколение) и не способны, например, подавать электронные жалобу или заявление, что может явиться препятствием к свободному доступу к правосудию. Кроме того, как показывают исследования

\footnotetext{
${ }^{16}$ Подобные системы предотвращения потери данных (или DLPсистемы) уже применяются России в сфере малого и среднего бизнеса для защиты конфиденциальной информации организаций от посторонних лиц. См.: Синельников А. Защита от утечки информации // Финансовая газета, №23, июнь 2011 г.
} 


\section{Право и политика $1(157) \cdot 2013$}

некоторых молодых ученых, в правоохранительной сфере встречаются лица, которые не в полной мере овладели навыками использования компьютерных технологий ${ }^{17}$.

В-шестых, потребуется разрешить вопрос, связанный с проставлением на электронные материалы уголовного дела печатей следственных, экспертных, судебных и иных органов для их заверения, так как в системе электронной подписи отсутствуют цифровые формы печатей, а новым Федеральным законом «Об электронной подписи» ${ }^{18}$, к сожалению, никоим образом не урегулирован данный вопрос.

В-седьмых, стоит добавить, что переход от старых технологий к новым, в том числе и к электронной форме уголовного дела должен быть плавным и последовательным, т.е. без каких-либо резких переходов. Не исключено, что некоторое время на начальном этапе параллельно будут существовать две формы уголовного дела, потому что данный фактор необходим для того, чтобы дать новой технологии возможность «притереться» и устранить многие ошибки и недостатки в процессе функционирования электронной формы уголовного дела.

В-восьмых, для развития и внедрения электронной формы уголовного дела необходима поддержка, в первую очередь, федеральных органов исполнительной власти, в частности Правительства РФ, наряду с правоохранительными органами. Например, только для модернизации досудебного уголовного судопроизводства необходимо принять отдельную федеральную целевую программу для развития, обновления и совершенствования следственного аппарата и органов дознания с тем, чтобы на стадии предварительного расследования появились передовые высокие технологии. Без подобной федеральной целевой программы невозможно внедрить и процессуально закрепить возможность применения электронной формы уголовного дела.

Можно предположить, что электронная форма дела будет в дальнейшем востребована по гражданским и административным делам. Не исключено, что подобная электронная форма может выйти за рамки судопроизводства, где и будет востребована в различных сферах государственных органов, в том числе и под эгидой системы «Электронное правительство».

\footnotetext{
${ }^{17}$ Так, в своем диссертационном исследовании С.М.Плешаков относительно работы экспертных учреждений отмечает следующее: «анкетирование экспертов показало, что $60 \%$ из числа опрошенных не владеют информацией о компьютерных программах экспертного назначения, не говоря уже о применении их при производстве судебных экспертиз» // Плешаков С.М. Современные экспертные технологии в деятельности судебно-экспертных учреждений России: автореферат дис. ... кандидата юридических наук; 12.00.09. Нижний Новгород, 2007. С.22.

${ }^{18}$ См.: Федеральный закон от 06.04.2011 №63-Ф3 (ред. от 10.07.2012) «Об электронной подписи» // Собрание законодательства РФ. 11.04.2011. №15. Ст. 2036.
}

Таким образом, исходя из вышеизложенного, стоит отметить следующие выводы:

1. Как показало исследование, ряд ученых и практикующих специалистов всецело отдают предпочтение новым и прогрессивным технологиям в уголовном судопроизводстве, в том числе и электронной форме уголовного дела, отмечая при этом их значимость для обеспечения гарантированного соблюдения многих прав и свобод человека и гражданина в уголовном судопроизводстве.

2. Вместе с тем федеральные целевые программы, посвященные развитию судебной системы в России, содержат ряд предпосылок, «подталкивающих» судебную реформу к внедрению электронного уголовного дела. На наш взгляд, было бы целесообразным уже в ближайшие годы разработать федеральные целевые программы для развития и совершенствования досудебного уголовного судопроизводства, ведь, как показало исследование, преимущества современных технологий, в первую очередь электронной формы уголовного дела, неоспоримы.

3. Возможности современных технологий позволят уже в ближайшем будущем создать первые рабочие прототипы электронных носителей для уголовных дел, впрочем, как и саму систему электронного уголовного дела, на тестирование и отладку которых может уйти несколько лет, прежде чем займет свое место в уголовном судопроизводстве.

4. Имеющееся в уголовно-процессуальном законодательстве заделы по использованию современных технологий позволят технически испытать первые образцы электронного уголовного дела в ближайшее десятилетие без каких-либо существенных изменений Уголовнопроцессуального кодекса РФ. Однако в любом случае в будущем потребуется законодательно урегулировать возможность применения данной технологии, заблаговременно устранить барьеры и разрешить проблемные ситуации, которые могут возникнуть при внедрении электронной формы уголовного дела.

\section{Библиография}

1. Абдулвалиев А.Ф. О необходимости использования Интернет-сайтов судов общей юрисдикции с целью формирования правовой культуры в молодежной среде // Современное состояние государственной молодежной политики: опыт и проблемы: Материалы Региональной научно-практической конференции / под ред. Исуповой Е.А. - Нижневартовск: Изд-во НГГУ, 2011. С.3-10.

2. Гарифуллина А.Х., Сухарева О.С. Электронный протокол как новый вид доказательства и новый элемент удостоверительного аспекта уголовного судопроиз- 
водства // Вестник Казанского юридического института МВД России. 2012. № 9. С. 111-117.

3. Интернет-конференция Генерального директора Судебного департамента при Верховном Суде Российской Федерации Гусева Александра Владимировича «Актуальные вопросы деятельности Судебного департамента при Верховном Суде Российской Федерации: проблемы и перспективы». 10.08.2011. // URL: www.garant.ru (дата обращения: 25.10.2012).

4. Настольная книга военного прокурора: пособие (под общ. ред. заместителя Генерального прокурора Российской Федерации С.Н. Фридинского). М.: «За права военнослужащих». М.: 2012.

5. Плешаков С.М. Современные экспертные технологии в деятельности судебно-экспертных учреждений России: автореферат дис. ... канд. юрид. наук; 12.00.09. Нижний Новгород, 2007. С.5-6, 22-23.

6. Тульская О.В. Некоторые проблемы использования электронных документов в качестве доказательств в уголовном судопроизводстве // Вестник Академии Генеральной прокуратуры РФ. №6 (14). - 2009. С.74-79.

\section{References (transliteration):}

1. Abdulvaliev A.F. O neobkhodimosti ispol'zovaniya Internet-saytov sudov obshchey yurisdiktsii s tsel'yu formirovaniya pravovoy kul'tury $\mathrm{v}$ molodezhnoy srede // Sovremennoe sostoyanie gosudarstvennoy molodezhnoy politiki: opyt i problemy: Materialy Regional'noy nauchno-prakticheskoy konferentsii / pod red. Isupovoy E.A. - Nizhnevartovsk: Izd-vo NGGU, 2011. S.3-10.

2. Garifullina A.Kh., Sukhareva O.S. Elektronnyy protokol kak novyy vid dokazatel'stva i novyy element udostoveritel'nogo aspekta ugolovnogo sudoproizvodstva // Vestnik Kazanskogo yuridicheskogo instituta MVD Rossii. 2012. № 9. S. 111-117.

3. Pleshakov S.M. Sovremennye ekspertnye tekhnologii v deyatel'nosti sudebno-ekspertnykh uchrezhdeniy Rossii: avtoreferat dis. ... kand. yurid. nauk; 12.00.09. Nizhniy Novgorod, 2007. S.5-6, 22-23.

4. Tul'skaya O.V. Nekotorye problemy ispol'zovaniya elektronnykh dokumentov $\mathrm{v}$ kachestve dokazatel'stv v ugolovnom sudoproizvodstve // Vestnik Akademii General'noy prokuratury RF. №6 (14). - 2009. S.74-79. 